
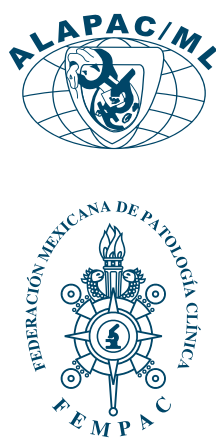

* Editor de la Revista Mexicana de Patología Clínica y Medicina de Laboratorio.

Correspondencia: Dr. Alberto Zamora Palma

E-mail: albertoz100@ hotmail.com

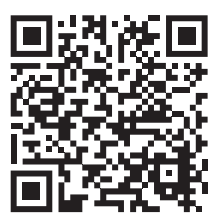

\title{
EDITORIAL
}

\section{Paradigmas de supervivencia de la humanidad}

\author{
Paradigms of survival of humanity
}

\section{Zamora Palma Alberto*}

U no de los fines fundamentales de la humanidad es la supervivencia. Los humanos con características anatómicas modernas, Homo sapiens, surgieron hace entre 300,000 y 200,000 años ${ }^{1}$ y durante este tiempo el hombre ha enfrentado guerras nacionales y mundiales, bombas atómicas, catástrofes naturales como los terremotos, tsunamis, incendios y la contaminación ambiental. Recientemente, nos hemos encontrado con el cambio climático y el calentamiento global, del mismo modo, el uso indiscriminado de antimicrobianos se ha convertido en un problema de salud pública mundial. La Organización Mundial de la Salud ha establecido que cuando ya no se pueden tratar las infecciones con los antibióticos de primera línea, es necesario utilizar fármacos que resultan cada vez más caros y, como consecuencia, los periodos de la enfermedad y los tratamientos son más prolongados, también se incrementan los costos por las complicaciones generadas, todo esto, en general, incrementa los costos de la atención sanitaria y se convierte en una carga económica para las familias y la sociedad. ${ }^{2}$

En este mismo sentido, la resistencia para uso de las vacunas, en especial, en esta pandemia contra el virus SARS-CoV-2 y las nuevas cepas, resulta un problema importante que pone a trabajar de más y a consumir recursos que fueron dedicados en primera instancia a la atención sanitaria en México, pero además, consume otros recursos nacionales.

Algunas de las consecuencias por no vacunarse son las siguientes: 1 . Se alcanzará tardíamente la inmunidad colectiva, probablemente a finales del 2022; 2. Aumentará la necesidad de aumentar el número de refuerzos, 3 . En España, donde las condiciones para vacunar a la población son óptimas, el atraso en la vacunación tiene un costo por implementación de medidas de bloqueo del virus de 63 millones de euros cada tres semanas, habría que ver cómo se reflejaría este impacto en México. ${ }^{3}$

Desde la perspectiva del laboratorio debemos estar preparados y atentos para dar una respuesta oportuna, en el entendido de que la pandemia no ha terminado y que aún no sabemos exactamente cómo se va comportar esta enfermedad que sigue desafiando a humanos y no humanos incluso.

\section{REFERENCIAS}

1. https://www.bbc.com/mundo/noticias-50222475

2. https://www.who.int/es/news-room/fact-sheets/detail/ resistencia-a-los-antibi\%C3\%B3ticos

3. https: solunion.com/impact-economico-del-atrasoen-las-vacunas-carrera-contra-reloj-para-salvar-la economía/

Citar como: Zamora PA. Paradigmas de supervivencia de la humanidad. Rev Mex Patol Clin Med Lab. 2021; 68 (2): 44. https:// dx.doi.org/10.35366/103337 